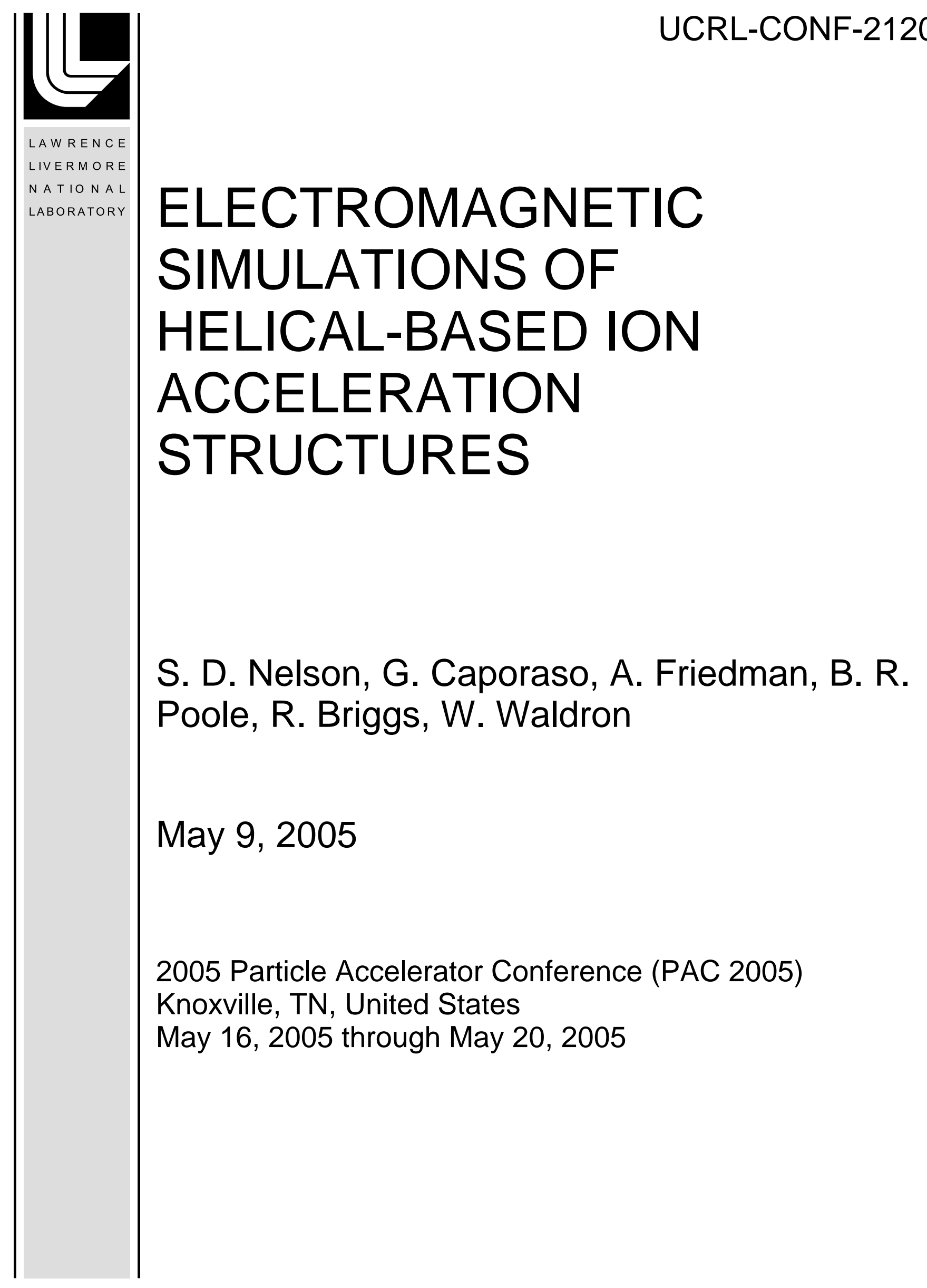


This document was prepared as an account of work sponsored by an agency of the United States Government. Neither the United States Government nor the University of California nor any of their employees, makes any warranty, express or implied, or assumes any legal liability or responsibility for the accuracy, completeness, or usefulness of any information, apparatus, product, or process disclosed, or represents that its use would not infringe privately owned rights. Reference herein to any specific commercial product, process, or service by trade name, trademark, manufacturer, or otherwise, does not necessarily constitute or imply its endorsement, recommendation, or favoring by the United States Government or the University of California. The views and opinions of authors expressed herein do not necessarily state or reflect those of the United States Government or the University of California, and shall not be used for advertising or product endorsement purposes. 


\title{
ELECTROMAGNETIC SIMULATIONS OF HELICAL-BASED ION ACCELERATION STRUCTURES*
}

\author{
Scott D. Nelson, George Caporaso, Alex Friedman, Brian R. Poole, Lawrence Livermore National \\ Laboratory (LLNL), Livermore, CA 94550, U.S.A., Richard Briggs, SAIC, Alamo, CA, 94507, \\ U.S.A., William Waldron, Lawrence Berkeley National Laboratory, Berkeley, CA 94720, U.S.A.
}

\section{Abstract}

Helix structures have been proposed [1] for accelerating low energy ion beams using $\mathrm{MV} / \mathrm{m}$ fields in order to increase the coupling efficiency of the pulsed power system and to tailor the electromagnetic wave propagation speed with the particle beam speed as the beam gains energy. Calculations presented here show the electromagnetic field as it propagates along the helix structure, field stresses around the helix structure (for voltage breakdown determination), optimizations to the helix and driving pulsed power waveform, and simulations showing test particles interacting with the simulated time varying fields.

\section{INTRODUCTION}

The helical structures are composed of wire wound around an insulating hollow core. Inside the core is the vacuum region for the ion beam. Outside the core is a dielectric insulating material (e.g. oil, or a cast material) which prevents breakdown between the helical windings and the metallic outer cylinder (see Figure 1). In this configuration, feeds penetrate through the outer cylinder and directly drive the helix.

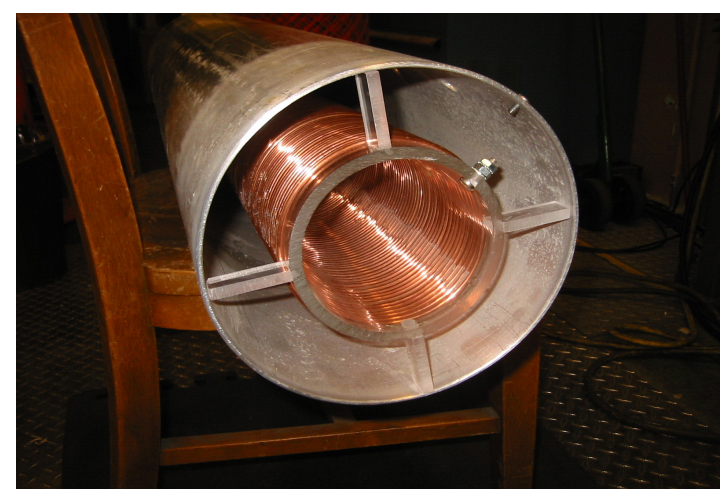

Figure 1: Early prototype of the helical accelerating structure of Briggs, Waldron, and Reginato [1]

The simulations were performed in $4 \mathrm{D}(\mathrm{x}, \mathrm{y}, \mathrm{z}, \mathrm{t})$ using finite difference time domain (FDTD) calculations [2]. In addition to discrete wires, sources, and loads which are included in the code, specific waveforms tailored to producing the desired accelerating gradient were specified for the source that drives the helix. Voltage waveforms are selected such that $\mathrm{E}=\mathrm{dV} / \mathrm{dz} \rightarrow \mathrm{dV} / \mathrm{dt}$, so a linear ramp in voltage will produce a constant accelerating field.
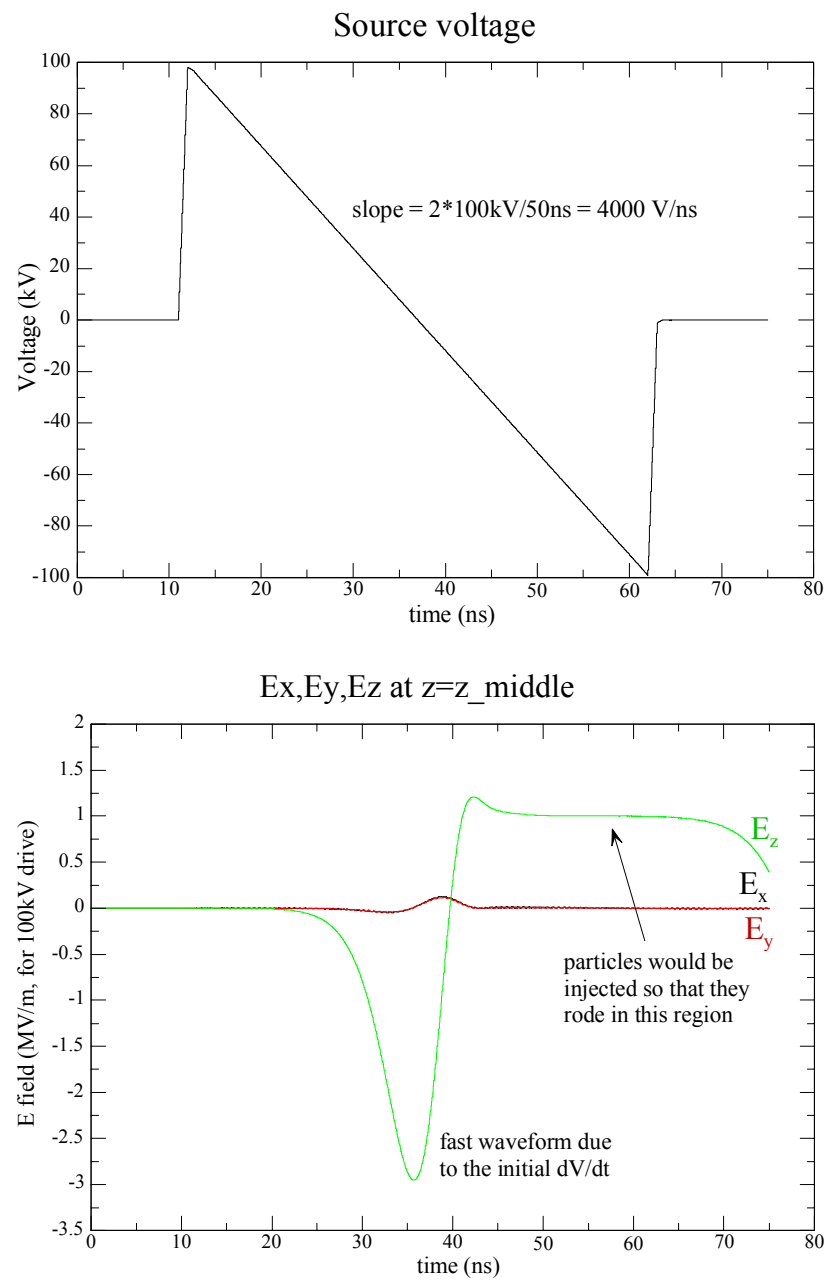

Figure 2: A canonical drive voltage waveform and the associated accelerating electric field produced in the helix.

The electric field that was produced had a large spike at $35 \mathrm{~ns}$ and $85 \mathrm{~ns}$ (not shown) due to the leading and trailing edges of the voltage waveform. This waveform was used for expediency, but in general the leading and trailing edges should be slower than the main ramp-pulse in order

*This work was performed under the auspices of the U.S. Department of Energy, the University of California, Lawrence Livermore National Laboratory under Contract No. W-7405-Eng-48. 
to minimize the peak electric field in the structure. Also note the transverse coupling $\left(\mathrm{E}_{\mathrm{x}}, \mathrm{E}_{\mathrm{y}}\right)$ from the leading edge of the voltage pulse. This is caused by the angle formed between the $0^{\circ}$ and $180^{\circ}$ points on a single helix turn.

\section{SIMULATION BACKGROUND}

The FDTD simulations of the helical structure used the thin-wire model for the helix windings wrapped around the beam tube. In the calculation, computational cells were set with a transverse cross section $(\Delta x, \Delta y)$ defining the refinement of the curvature of the helix while the longitudinal $\Delta \mathrm{z}$ was selected such that the pitch-to-pitch spacing was well resolved. In these cases, 50 transverse cells (in each dimension) spanning the beampipe and 10 cells longitudinally (pitch-to-pitch) gave acceptable results. Excitation waveforms were either simple ramp functions of the form shown in Figure 2, or corresponded to actually waveforms used as part of the experimental tests as shown in the next section in Figure 4.

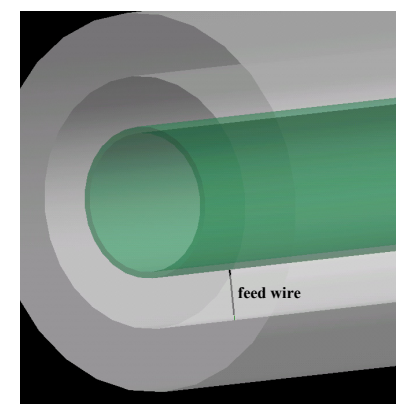

Figure 3: the feed wire attached to the helix at a point a short distance into the supporting beam tube.

\section{EXPERIMENTAL DATA}

Early experimental data [3] confirming the validity of the various models illustrates the benefits of full wave time domain simulations. These simulations include the source and feed effects, inductances near the beginning of the helix, transmission line effects, turn-to-turn coupling, cross-turn coupling, and interactions with the enclosure. For comparison purposes, Figure 4 shows the comparison between the simulation data and the results from the experiment for the input and output waveforms to the helix.
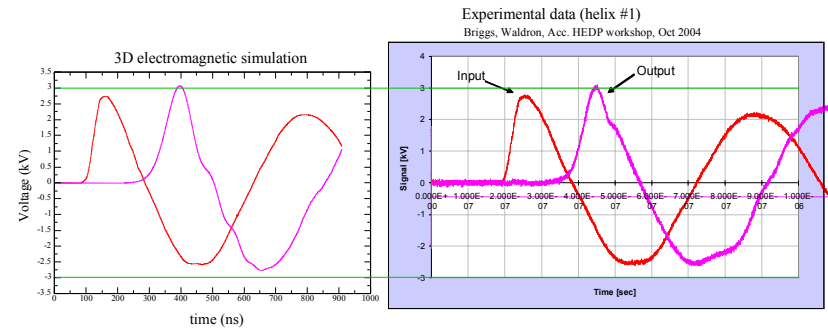

Figure 4: comparison between simulation result and experimental data from Briggs, Waldron [3] for the initial prototype helix

\section{RESULTS}

Initial work with the ramp waveform examined matching the ion beam from an injector into the input of the helical structure. Field sensors at locations indicated in Figure 5a show thirteen measurements points to illustrate the transition from outside of the helix to inside of the helix. The electric field plots shown in Figures 5b,c show the fields in the two groups of measurement points as indicated. Note that there is one point of overlap between the two plots.
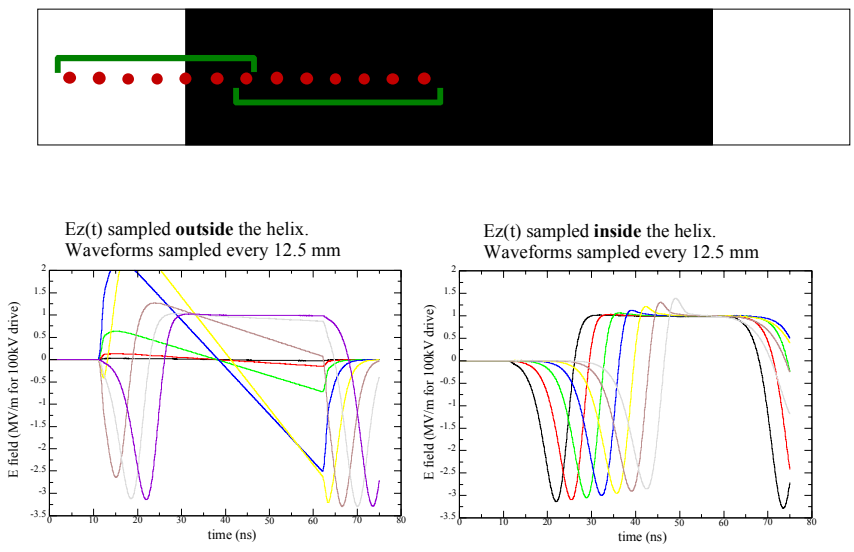

Figure 5a,b,c: the measurement points inside and outside of the helix illustrate the unbalanced fields immediately outside of the helix.

At this point, it is envisioned that the ions would be injected at a specific time to catch the accelerating portion of the helical fringe field and/or the ion injector would overlap the helix. From the time domain waveforms, it is apparent that if ions are injected with an initial velocity above $(0.55 \%) \mathrm{c}=0.0055 \times 310^{8} \mathrm{~m} / \mathrm{s}$, and are timed to reach the flat-top of the accelerating field at a spatial point just inside the helix, then the ions will get from the $\mathrm{z}=\mathrm{z}_{0}$ points (at the helix boundary) to the $\mathrm{z}=\mathrm{z}_{0}+25 \mathrm{~mm}$ point ( $25 \mathrm{~mm}$ inside the helix) in $15 \mathrm{~ns}$ thus avoiding the decelerating pulsed caused by the leading edge of the ramp waveform. Note however that this ramp waveform's leading edge is much larger than what would be used in practice. It is also fortuitous that there is no decelerating field outside of the helix while the drive waveform is building up. Thus particles outside the of helix can have injection energies corresponding to velocities nominally less than $(0.55 \%)$ c as long as they gain sufficient energy from spatial points $37.5 \mathrm{~mm}$ upstream of the helix (e.g. $\mathrm{z}=\mathrm{z}_{0}-37.5 \mathrm{~mm}$ to $\mathrm{z}_{0}$ ) to achieve a velocity of $(0.55 \%)$ c by the time they reach the helix boundary (see Figure 6). Also in this example, in order to track the advancing accelerating wavefront once inside the helix, it is necessary to have a velocity of $(1.2 \%) \mathrm{c}$ at the $\mathrm{z}=\mathrm{z}_{0}+25 \mathrm{~mm}$ point or to have an earlier injection time and accept the "slippage" along the advancing accelerating wavefront.

Different helix and ion injector configurations have different initial ion velocities, but care must be taken in 
catching the accelerating waveform into the helix before any decelerating waveforms are produced at the mouth of the helix. Once the accelerating waveform is caught at the corresponding spatial position, the ions have some latitude of allowable "slippage" due to the flat top of the accelerating field.

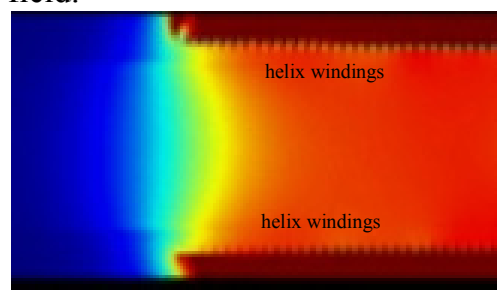

Figure 6: an expanded view of the input to the helix shows the helix windings and the fringe region outside of the helix.

\section{Riding the accelerating pulse}

After the accelerating pulse established itself, it then propagated down the length of the helix. Figure 7 shows the accelerating electric field $\left(\mathrm{E}_{\mathrm{z}}\right)$ along the centerline of the helix as the pulse propagated down the helix.
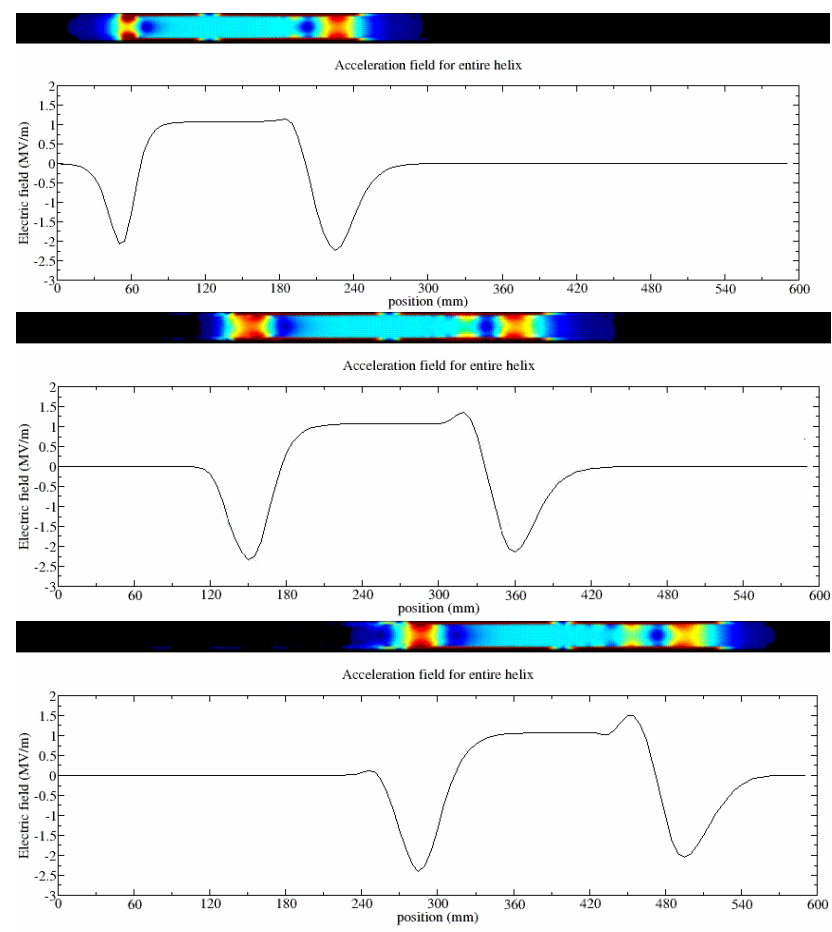

Figure 7: spatial snapshots and the magnitude of the electric field in the plane of a longer helix are shown for $63 \mathrm{~ns}, 102 \mathrm{~ns}$, and $141 \mathrm{~ns}$ with $\mathrm{v}=(1.15 \%) \mathrm{c}$.

Ions were injected into the particle simulation code developed as part of [4] with an initial energy of $1 \mathrm{MeV}$ and an injection time selected in order to catch the end of the accelerating waveform (18ns in this case) using the prescription from the previous section. For simplicity the helix had a constant pitch, so as the ions gained energy (velocity) they advanced up the accelerating waveform. However the accelerating waveform had a flat top so this advancement was ignored. The phase space output of the ion bunch is shown in Figure 8.
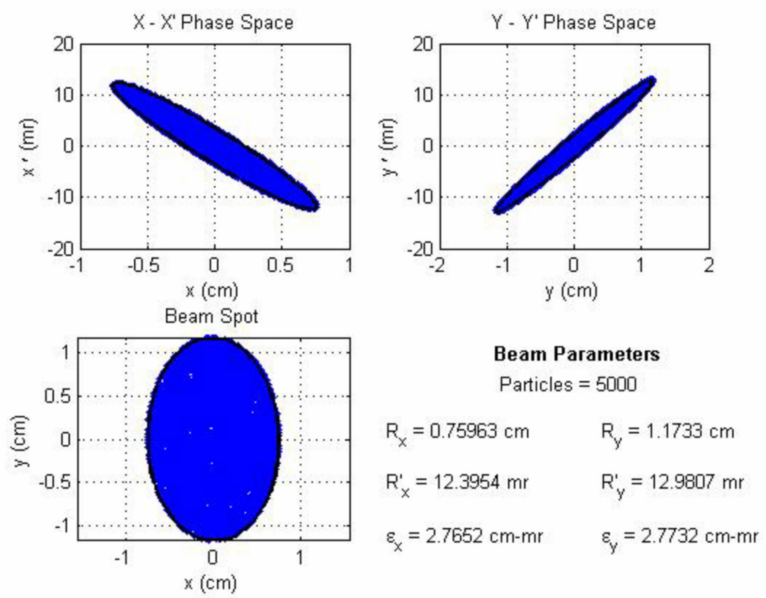

Figure 8: the phase space diagram of the output ion bunch shows a well behaved beam after $\sim 0.5 \mathrm{~m}$ of acceleration.

\section{FUTURE WORK}

There are several activities planned for the upcoming year for the detailed 3D EM calculations. These include varying the helix wire diameter, confirming the analytic dispersion relations, determining all of the parasitic circuit parameters for inclusion into the WARP code [5], studying the dielectric loading effects around the outside of the helix, further work in the input section to the helix (near the injector), and better matching of the helix output section.

\section{CONCLUSIONS}

Through these simulations, helical structures have been shown to perform well with voltage ramp excitation pulses and appear as a promising way to efficiently couple high current pulsed power systems (kiloamps) to high current ion beams (amps).

\section{REFERENCES}

[1] R. Briggs, L. Reginato, W. Waldron, "Helical Pulseline Structures for Ion Acceleration," this conference.

[2] REMCOM Corp., 315 S. Allen St., Suite 222, State College, PA 16801

[3] R. Briggs, W. Waldron, Accelerator HEDP Workshop, Lawrence Berkeley National Laboratory, October 26-29, 2004.

[4] B. R. Poole, Y.-J. Chen, "Particle Simulations of DARHT-II Transport System," 2001 Particle Accelerator Conference (PAC01), June 18-22, 2001, Chicago, Illinois, Lawrence Livermore National Laboratory, UCRL-JC141921, 2001.

[5] D. Grote, et. al., "Particle Simulations of Acceleration Schemes for High-Current, Short-Bunch, Ion Beams," this conference. 